\title{
Meaning formation in younger schoolchildren with speech disorders in the context of didactic approach
}

\author{
Elena Matsyuk $^{1 *}$, Elena Belova ${ }^{2}$ \\ ${ }^{1}$ Don State Technical University, Faculty "Psychology, Pedagogy and Defectology", \\ 344000 Rostov-on-Don, Russian Federation \\ ${ }^{2}$ Moscow state University of food production, Moscow, Russian Federation
}

\begin{abstract}
The article reviews the content and continuity of didactic conceptions of teaching primary school children with disabilities in modern conditions. The authors examine the nature of the reasons for poor performance of students with speech disorders, and reveal the contradictions of the integrative approach in education, as well as the possibilities of resolving these contradictions through the use of meaning pedagogy. The problem of designing an effective teaching model for primary schoolchildren with speech disorders is posed which can contribute to the formation of a positive image of the "Self", the formation of an emotion- and value-related attitude to reality and adequate perception of oneself in the world. The authors suggest that children with speech disorders with potential prerequisites for intellectual development are able to overcome communicative, cognitive and personal barriers to learning much better when provided didactic conditions for triggering the mechanism of meaning initiations in comparison with children with other manifestations of limited health abilities. An attempt has been made to create a meaningful didactic model of teaching primary school children with speech disorders in the context of inclusive education, that allows to increase the efficiency of the educational process and the social adaptability of children with speech disorders in society.
\end{abstract}

\section{Introduction}

Modern educational paradigm that develops in the context of humanistic ideas is oriented towards a student of a new formation, the "digital generation." Under the influence of personality-centered pedagogy and psychologization of approaches to the learning process, modern didactics does not seek to provide the student with knowledge, abilities and skills but

${ }^{*}$ Corresponding author: elenamacjuk@yandex.ru 
defines education as a process that facilitates a person's entering his or her "Self"representation. "Self" serves as a source of the semantic activity of consciousness. Such an education forms a value-semantic and spiritual component of the student's personality and is concordant with a change in the course of educational policy throughout the world [1]. In the context of value orientations of our state and society regarding education, the idea of creating an educational space that would correspond to the possibilities and various needs of students enjoys full support. At school children are taught to maintain a friendly attitude to their peers with disabilities (PD), thus the school becomes an institution where new values are formed [2].

The scientific concepts of "integration" and "inclusion" appeared in the works of modern and foreign authors relatively recently, in the late 60s of the XX century. In the Russian practice of inclusive education, there is an opposition between the opinion on the differentiated selection of students who can be included in the learning process along with healthy peers (N.N. Malofeev, I.M. Bgazhnokova, L.M. Shipitsina) and the opinion that society needs to change in order to integrate any child with disabilities into the educational space. (S.V. Alekhina, E.N. Kutepova, E.I. Leongard, E.V. Samsonova, A.Y. Shemanov). Chirkina G.V. emphasized that in spite of a fairly good level of organization of special (remedial) education and upbringing of children with disabilities, compensatory education in a secondary school is faced with the problems of providing an individual approach and phobic manifestations from those around people with special needs [3].

In search of didactic systems that could provide the shortest ways to overcome barriers to learning (including those related to health limitations) and the students' mastering the achievements, knowledge and experience of previous generations, Russian psychologists A.G. Asmolov et al developed the idea of education endowed with meanings. As a result, the idea of the possibility of influencing the formation of the semantic sphere of personality came into being [4]. Some attempts were made to study the process of formation of the meaning attitudes of thea personality, understanding the mechanism of developing meaning formations in the consciousness of the student. The researchers concluded that the process of bringing the learned material to the level of personal meanings is difficult for the student, since the process of revealing and integrating, "decrystallizing" meanings is difficult. The model of meaning forming education can not only ensure that internal and external barriers to learning are overcome, but also, at the level of personal qualities, go beyond the limits of one's "Self", initiate the formation of higher meanings and meaning orientation.

The specifics of the educational process content in the meaning-forming model of education is that the structural unit is represented not by the knowledge, or process of thinking or creative activity but by the very meanings. "Meanings, therefore, can become both knowledge, and ways, and problems depending on their real existence in the pedagogical context... In the knowledge-based model, reproductive activity is carried out most of the time, the activity-based model is all about object-oriented activity, the problem-based model is about thought-related activity, then in meaning-forming model, main activity is the activity of experience" [5, p. 388].

Meaning techniques used in the educational process and oriented at the personal mechanisms of individual cognition, bring learning to a new level. The most valuable result of the development of ideas about education, endowed with meanings, in the 2000s were represented by the concepts of meaning-centrism (I.V. Abakumova, V.T. Fomenko, P.N. Ermakov, I.A. Rudakova) and meaning-didactics ( I.V. Abakumova, V.T. Fomenko, P.N. Ermakov) The author of the meaning-forming model of the educational process, Abakumova I.V., emphasizes that the very logic of the development of modern psychology and didactics leads to the study of the meaning-formation process in the educational process and that through classes that contribute to meaning development, one can track and describe the development of the child [6]. 
In confirmation of the things stated above, the meaning-didactic school of I.V. Abakumova has accumulated sufficient theoretical and empirical material that explores various models of the educational process according to the criterion of the ability to initiate students' meaning formation. The conclusion states that by incorporating all other models, the meaning-forming model is assimilated with them and cannot be considered a special

model, but is considered as a general one, that extends into to various teaching models (dogmatic, knowledge-based, problem-based) [5,6,7]. The authors of the meaning-didactic conception have identified and examined in detail the goal-oriented, content-related, technological and organizational parameters $[2,5,6]$.

Expanding the field of study of the meaning-related sphere of students and the opportunities of managing meanings, meaning-pedagogy is faced with a range of levels of students' personal meanings and transformations of meaning formation. In particular, in the process of research conducted under the scientific supervision of I.V. Abakumova, a zero level of meanings was identified in children and adolescents with disabilities: deaf boys and girls, children with communicative disorders from behavior alterations of autistic spectrum and hyperactivity. The validity of the research of this scientific school is supported by the accessibility and transparency of the methods used in teaching, and is confirmed by the results of practical application $[5,8,9]$.

For instance, Kuzenko S.S., in her examination of the deformation of the semantic sphere in adolescents with communicative and personality disorders, indicates that adolescents with autistic traits aggressively dominate the relationship. Values and needs that make up meaning regulation, are formed in a deformed and non-structured way, and therefore the source of the meaning-forming process can not be discovered. For adolescents with hypermobility, one can register some disruptions in the balance of the semantic sphere due to the disruptions in the differentiation of the communicative orientation [8].

Studies of the meaning sphere of boys and girls with hearing loss, conducted by Koltunova E.A revealed more than ten features of the semantic sphere of this category of students in comparison with the ordinary hearing population.[9] Among them one can list the delay in the formation of the meaning sphere, the uniqueness of the content side, the negative attitude to the world and society, vague quality of life plans. Researchers developed models for teaching adolescents with disabilities from the perspective of a meaningful didactic approach and the possibility of influencing the formation of the meaning sphere in conditions of deficiency. They prepared guidelines for secondary school teachers.

However, despite the obvious interest of psychologists and teachers in the development of the semantic sphere in children and adolescents with disabilities, there is a shortage of research on the features of meaning development in children with speech disorders.

Speech components (phonetic, lexical, grammatical and semantic one) are interconnected in each period of the child's speech development, therefore the inclusion of speech at all stages of educational activity serves the implementation of a systematic approach in the education of students with speech disorders. A systematic approach, along with a differentiated and active approach, formed the basis for the development of an adapted basic educational program for primary general education (further ABEP PGE) for students with severe speech disorders (SSD). The idea of capturing the parameter "special educational needs of a child with a particular speech disorder (special educational needs, SEN)" belongs to professor G. Chirkina who emphasized the need for innovative approaches to teaching children with speech disorders [3]. Analyzing the modern education trends for children with severe speech disorders (SSD), L. Lopatina, notes the special importance of the national educational standards developed by G. Chirkina for children with disabilities, as the author of the standards "provides for wide variability in the organization and content of education, ensuring the satisfaction of the special educational needs of all groups of students with SSD, 
the creation of special conditions aimed at implementing the principles of continuity of the process of psychological and pedagogical support of education” [10, p. 55].

\section{Results and discussion}

Analyzing the theoretical base and advanced pedagogical experience in the field of inclusive education, I.V. Abakumova, P.N. Ermakov, L.V. Kosikova conclude that the task of fullfledged inclusion of children with disabilities in the process of school education may find solution in developing a positive image of one's «Self» and in the formation of an emotionalvalue attitude to reality and an adequate perception of oneself in the world around. [2] Since children with disabilities do not have educational values in the top positions of their priority system (due to the need to maintain physical health), interaction as a process and the result of joint learning may become for them the leading mechanism for overcoming destructive attitudes and complexes. However, for children with speech disorders, there is an insufficient formation of life competencies due to the presence of communicative barriers. Due to the insufficient development of methods of speech behavior in most children with speech impairment, social development is not fully formed. Children do not know how to choose communication strategies and tactics for solving problem situations. Nevertheless, most children with speech disorders have full prerequisites for intellectual development and the integration of a child with impaired speech development among peers is not as problematic as for other categories of children with disabilities.

In the study of specifics of the development of inclusive education, I.V. Abakumova, P.N. Ermakov and L.V. Kosikova emphasize that the inclusion of a student in the educational process should affect not only the level of his intellectual abilities but also his personal and social activity. Cognitive, communicative and personal barriers that correspond to the characteristics of students with the pathology of oral and written speech require the creation of didactic and psychological conditions for the meaningfulness of learning. This can be done by starting the mechanism of semantic initiations of self-relating in children with speech disorders.[2] The model of the initiation of meaning formation, in our opinion, is able to serve the purpose of increasing the academic success of this category of students. In our opinion, such a model should be presented in the form of three basic blocks: goal-oriented one, content-technological one and corrective-diagnostic one.

The goal-oriented component determines the value and meaning orientation of learning: attitude to the inclusive education as an integral cultural and educational space; introjecting children with speech pathology with ideas about a personality capable of a full life in society, the development of a culture of reflection, formation of self-knowledge and self-awareness skills, the development of a positive image of the "Self", the development of an emotionalvalue attitude to reality; the formation of social competence, communication skills and overcoming painful fixation on speech impairment and social deprivation.

The content - technological component includes the definition of the content and educational technologies of teaching, the organization of the learning process for younger students with speech disorders, taking into account their capabilities and individual and personal characteristics; stimulation of the motivational-meaningful sphere and the active personal position of a student with speech disorders as a subject of educational activity and social relations; ensuring overcoming of communicative barriers due to speech underdevelopment and prevention of secondary cognitive impairment; optimizing the interaction with peers and teachers for children with speech pathology.

Correction and diagnostic component includes a comprehensive diagnosis of the level of features of the personality development in children with pathology of speech and learning; collection and analysis of information on the influence of meaning techniques on the effectiveness of teaching children with speech disorders. 
To identify the features of the semantic sphere, to obtain integrated characteristics of personality formations and to influence them in order to increase the effectiveness of teaching younger schoolchildren with speech pathology, we have designed a technique that meets the following requirements: the technique should not be tiring for children 8-10 years old; should combine methods that complement each other in the disclosure and formation of the studied qualities of the meaning sphere of students; could confirm or refute the hypothesis about the possibility of improving the academic success of primary school students with speech disorders through the use of a meaning-didactic model of learning.

In developing the meaning-didactic model of teaching younger students with speech disorders, the following methods were used:

1) methods for the analysis of theoretical information: systematization of didactic literature on the assessment of the initiation of meaning components in the process of inclusive learning; comparative analysis and generalization of didactic approaches that examine the technologies of initiating students' meaning formations;

2) diagnostic methods for identifying the influence of techniques included in the designed methodology on the specifics of the meaning development of younger schoolchildren with disorders of speech and writing;

3) a training experiment to test the meaning-didactic model of the inclusive education of children with speech disorders;

4) methods for processing empirical results: qualitative methods, content analysis, expert evaluation, methods of mathematical statistics.

We used both standardized techniques and projective type techniques. The test "Selfportrait" (R. Burns), [11] were selected to identify the system of subjective values; AAA questionnaire - activity, adaptability, autonomy (E.N.Korneeva, M.I. Rozhkov) [12] - to study the characteristics and levels of socialization of younger schoolchildren with speech pathology; the methodology used to assess the emotional well-being of children (developed by the Latvian State University of Culture, VNIIFC Laboratory). When studying the transformations of the semantic sphere of younger schoolchildren with speech pathology, it is necessary to take into account communicative barriers in teaching this category of children. However, the varying degree of verbalization of the technique is also explained by the fact that the elements of the meaning sphere can be represented both in verbal and imagery form. The teacher, enriching and developing these images, activates the cognitive activity of the student with speech pathology and helps the student to transform the accumulated experience into new knowledge not by mechanical memorization, but by passing it through consciousness. Such technology does not only enhance the development of cognitive mental processes, but also strengthens the formation of a subjective representation of the picture of the world. Since the transformation of images and ideas takes place on the basis of forecasting and planning one's activities, and managing the formation of images, according to E. Bayeva, is possible through actions, the author concludes that meaning pedagogy helps to stimulate the development of imaginative thinking in the learning process and thereby may influence the manageability and controllability of images of a possible future [13]. When combining exercises and tasks for each stage of training, the experience of compiling creative development programs for children with general speech underdevelopment was taken into account (the concept of developing creative imagination in the "Young Wizards» program) [14].

\section{Conclusions}

Using the semantic didactic model of teaching younger school children with speech disorders in the context of inclusive education, we expect to obtain data that allows us to establish the features of the semantic structures of this category of children according to the following 
indicators: attitude to the world, attitude to microsocium, substantial aspects of self-esteem, emotional assessment of life prospects. We plan to evaluate the effectiveness of the use of the meaning didactic model of teaching primary school children with speech disorders from the standpoint of increasing the effectiveness of the inclusive education of children with spoken and written speech disorders.

\section{References}

1. M.Y. Chernyshev, A.M. Zhuravleva, Integration of Education. 4, 107-117 (2015)

2. I.V. Abakumova, P.N. Ermakov, L.V. Kosikova, Meaning sphere of adolescents: the specifics of its development under the conditions of inclusive education (CREDO, Moscow, 2016)

3. G.V. Chirkina, Uchyonye zapiski. Electronic scientific journal of Kursk State University. 2, 155-166 (2012)

4. A.G. Asmolov, B.S. Bratus, B.V. Zeygarnik, V.A. Petrovskiy, E.V. Subbotskiy, A.U. Kharash, L.S. Tsvetkova, Questions of Psychology. 3, 35-45 (1979)

5. Abakumova, Teaching and meaning: the place of meaning formation in the process of education (Publishing House of Rostov State University, Rostov-on-Don, 2003)

6. I.V. Abakumova, Meaning didactics: handbook for masters degree candidates of the psychology and pedagogy departments (Southern Federal University Press, Rostov-on-Don, 2008)

7. I.V. Abakumova, M.V. Godunov, D.V. Pen'kov, The strategies of meaning formation: the potential of modern research (CREDO, Moscow, 2019)

8. S.S. Kuzenko, Deformation of the meaning sphere in teenagers with communicative and personality disorders (Rostov-on-Don, 2008)

9. E.A. Koltunova, Psychological features of symbolisation in adolescent children with hearing impairment (Rostov-on-Don, 2015)

10. L.V. Lopatina, S.V. Nedolenko, S.B. Yakovlev, Logopedia. 2, 53-57 (2015)

11. R. Berns, The development of the concept of «I» and upbringing (Progress, Moscow, 1986)

12. E.N. Korneeva, Non-standart children. The integrative regulation of the educational interaction of schoolchildren with developmental delay, childrent from migrants families and gifted children (Akademia razvitia, Yaroslavl, 2007)

13. E. I. Bayeva, North Caucasian psychological journal. 4(12), 21-27, (2014)

14. A.E. Symanovsky, N.G. Ershova, Yaroslavl Pedagogical Bulletin. 4, 135-142 (2015) 